Revista ComSertões

\title{
Comunicação Popular: uma análise da Comissão Pastoral da Terra em Juazeiro-BA
}

Juliana MAGALHÃES ${ }^{1}$

Gislene MOREIRA ${ }^{2}$

\section{Resumo}

O presente artigo analisa a comunicação produzida pela Comissão Pastoral da Terra (CPT), em Juazeiro (BA). Fruto de uma observação-participante, o trabalho apresenta como referencial teórico autores como Peruzzo (1998), Martín-Barbero (1997) e Gohn (2003), utilizando como metodologia a análise de conteúdo. O trabalho teve como objetivo analisar aspectos da comunicação produzida pela entidade e sua contribuição para uma comunicação mais democrática e plural. Sustentamos a hipótese de que a CPT colabora para uma comunicação não hegemônica, entretanto há limitações que interferem nesse processo e são refletidas em sua produção.

Palavras-chaves: comunicação popular; movimentos sociais; democratização da comunicação.

\begin{abstract}
This article analyzes the communication produced by the Pastoral Land Commission (CPT), in Juazeiro (BA). Result of a participant observation, this work presents theoretical as authors like Peruzzo (1998), Martín-Barbero (1997) and Gohn (2003), and used as a content analysis methodology. The study aimed to analyze aspects of communication produced by the entity and its contribution to a more democratic and plural communication. Sustain the hypothesis that CPT collaborates with a non hegemonic communication, however there are limitations that interfere with this process and are reflected in his production.
\end{abstract}

\footnotetext{
${ }^{1}$ Estudante do $6^{\circ}$ período de graduação em Comunicação Social - Jornalismo em Multimeios, pela Universidade do Estado da Bahia. E-mail: jmm.lopess@ hotmail.com.

${ }^{2}$ Orientadora do trabalho. Professora do curso de Comunicação Social - Jornalismo em Multimeios, pela Universidade do Estado da Bahia.
} 


\section{Revista ComSertões}

Keywords: popular communication; social movements; democratization of communication.

\section{Resumen}

En este artículo se analiza la comunicación presentada por la Comisión Pastoral de la Tierra (CPT), en Juazeiro (BA). El resultado de una observación participante, este trabajo presenta teórica autores como Peruzzo (1998), Martín-Barbero (1997) y Gohn (2003), y se utiliza como una metodología la análisis de contenido. El objetivo del estudio fue analizar aspectos de la comunicación producida por la entidad y su contribución a una comunicación más democrática y plural. Sostener la hipótesis de que el CPT colabora con una comunicación no hegemónica, sin embargo, hay limitaciones que interfieren con este proceso y que se reflejan en su producción.

Palabras clave: comunicación popular; movimientos sociales; democratización de la comunicación.

\section{Introdução}

A humanidade vive em constantes processos de mudanças. Muitas dessas transformações são frutos de lutas e persistências de grupos sociais organizados que buscam alcançar determinados objetivos para o coletivo. Paralelo a esses movimentos, a comunicação está presente como uma ferramenta importante nessas conquistas.

É uma relação de reciprocidade, já que são os movimentos sociais que dão sustentabilidade a uma comunicação mais democrática, plural e a serviço realmente do povo. A Comunicação Popular está inserida nesse contexto e para compreender o que realmente se passa nela, precisamos entender que:

[...]Tem tanto mais a ver com o que se passa na fábrica e na taberna, nos melodramas e comícios de seu alarido, com suas faixas e panfletos, que com o que se passa no mundo dos periódicos mesmo; sem que isso signifique rebaixar a importância da revolução tecnológica (MARTÍN-BARBERO, 1997, p. 110). 


\section{Revista ComSertões}

Seguindo esse pressuposto, neste trabalho revisaremos o próprio conceito de comunicação popular, e o de movimentos sociais, em especial os do campo que faz parte do nosso objeto de estudo. Associamos a esta discussão também os debates sobre democratização das comunicações.

A análise deste trabalho é fundamentada nos materiais de comunicação produzidos pela Comissão Pastoral da Terra em Juazeiro (BA), organismo ligado à Comissão para o Serviço da Caridade, da Justiça e da Paz, da Confederação Nacional dos Bispos (CNBB), que assessora movimentos e comunidades rurais.

O estudo é fruto de uma observação-participante e é delimitado ao mês de março de 2013. Os objetivos são identificar a linguagem desses produtos, suas relações com as novas tecnologias, as condições em que eles são produzidos, a participação do público nas suas confecções e investigar a hipótese de que essa produção contribui para uma comunicação mais democrática, não-hegemônica e participativa.

\section{Comunicação Popular}

O termo "popular" abarca uma série de significados e compreensões ao longo tempo. Na época dos românticos, sociedade predominantemente burguesa, popular correspondia ao inverso do "culto", ou seja, aquilo que não era considerado cultura. Já no século XIX, a ideia romântica de povo sofre dissolução completa: pela esquerda, no conceito de classe social, e pela direita, no de massa (MARTÍN-BARBERO, 1997).

Para Peruzzo (1999) falar de comunicação popular envolve conotações diversas, destacando três correntes de estudos: popular-folclórico, que compreende as expressões culturais tradicionais que estão presentes no folclore, nas festas, danças, ritos e crenças; o popular-massivo, que está incluso no universo da indústria cultural; e o popularalternativo, que se situa no universo dos movimentos sociais.

Sobre a última corrente, que nasce no bojo dos movimentos populares vinculados as classes subalternas e que tece uma comunicação ligada à luta do povo por sua emancipação e garantia dos seus direitos, Peruzzo (1999, p. 119) afirma:

Essa corrente subdivide-se em duas linhas de pensamento: a) primeira, surgida no início dos anos oitenta, concebe a comunicação popular 
Revista ComSertões

como libertadora, revolucionária, portadora de conteúdos críticos e reivindicativos capazes de conduzir à transformação social [...]. b) a segunda, que apareceu no início dos anos noventa, em função das reelaborações ocorridas no âmbito da sociedade civil, tem uma postura mais dialética e flexível; considera que a comunicação popular pode inferir modificações em nível de cultura e contribuir para a democratização dos meios comunicacionais e da sociedade, a cuja transformação imediata ela não consegue levar, por suas limitações e contradições e sua inserção numa grande diversidade cultural, e por concretizar-se em espaço próprio ela não se contrapõe a comunicação massiva.

Além de alternativa, a comunicação popular também é denominada por alguns autores como comunitária, participativa, dialógica e horizontal. Entretanto, cabe ressaltar que o adjetivo "alternativo" também é usado no Brasil para se referir àqueles periódicos que oferecem uma leitura crítica e se contrapõe a grande imprensa.

Nesse contexto de lutas que a comunicação popular se desenvolve, ela apresenta como características: conteúdos críticos-emancipadores, denúncias das condições reais da vida, oposição às estruturas de poder, reinvindicações de acesso a bens de consumo coletivo, estímulo à participação e emancipação; espaço de expressão democrática, abertura de canais para segmentos sociais que não tem acesso as mídias massivas para expor suas ideias e reinvindicações; o povo como protagonista, suas organizações e ideias, e não a classe dominante; instrumento das classes subalternas, ela é vista como oposta ao modelo massivo que é taxado de manipulador e alienante aos interesses populares (PERUZZO, 1999).

Segundo Silva (2010, p. 41) a Igreja Católica foi de extrema importância na disseminação do debate sobre comunicação popular, sobretudo ao lançar a Campanha da Fraternidade de 1989 com o tema "Comunicação para a verdade e a paz". O foco dessa campanha era discutir as influências negativas e positivas dos meios de comunicação no comportamento das pessoas e a participação popular na elaboração e execução de políticas de comunicação.

\section{Movimentos Sociais e Populares}

As desigualdades, sejam elas no âmbito social, político, racial, ou de gênero, entre outras, permeiam a história das sociedades. A oposição a essas disparidades 


\section{Revista ComSertões}

também. Ela se apresenta como forma de interferir no processo histórico com a inserção de novos sujeitos. Os movimentos sociais têm sido considerados por vários analistas como elementos e fontes de inovações e mudanças sociais, e reconhecidos como detentores de saberes próprios decorrentes de suas práticas cotidianas (GOHN, 2002, p.189).

No Brasil, temos registros de grandes movimentos reivindicatórios desde o século XVI com o Quilombo dos Palmares (1960-1695), depois o Movimento da Cabanagem (1831-1840) e a Greve de 1917. Na contemporaneidade, os movimentos viveram um boom na década de 1970/80 e uma ressignificação nos anos de 1990, abrangendo uma ampla pluralidade de atores e dando origem a novas organizações com caráter mais institucionalizado. Sobre a flexibilidade dos movimentos sociais, Gohn (2002, p. 189) afirma:

A presença dos movimentos sociais é uma constante na histórica política do país, mas ela é cheia de ciclos, com fluxos ascendentes e refluxos (alguns estratégicos, de resistência ou rearticulação em face a nova conjuntura e as novas forças sociopolíticas em ação). $\mathrm{O}$ importante a destacar é esse campo de força sócio-política e o reconhecimento de que suas ações impulsionam mudanças sociais diversas. O repertório de lutas que eles constroem, demarcam interesses, identidades, subjetividades e projetos de grupos sociais.

As definições clássicas sobre movimentos sociais apontam como características básicas destes: identidade própria, opositor definido e articulação em torno de um projeto de vida ou sociedade. Eles possuem certa continuidade e permanência, e historicamente tem contribuído para organizar e conscientizar a sociedade. Para Gohn (2011, p. 337) há neles uma ressignificação dos ideais clássicos de igualdade, fraternidade e liberdade:

A igualdade é ressignificada com a tematização da justiça social; a fraternidade se retraduz em solidariedade; a liberdade associa-se ao princípio da autonomia - da constituição do sujeito, não individual, mas autonomia de inserção na sociedade, de inclusão social, de autodeterminação com soberania.

Os movimentos populares utilizam diferentes estratégias para concretizar suas ações, que variam de denúncias a marchas, passeatas, mobilizações e ocupações. 


\section{Revista ComSertões}

Atualmente, as redes sociais também foram apropriadas por esses movimentos, que utilizam a internet como nova ferramenta.

Expressões como movimentos sociais, coletivos, populares, entre outras, são usados sem distinção, o que reflete a grande diversidade e heterogeneidade desses grupos. Para Peruzzo (1999) essas organizações se agrupam em torno de objetivos que estão vinculados a determinado assunto, são eles: ligados aos bens de consumo coletivo (associação de moradores), envolvidos com a questão da terra (Movimento dos Sem Terra), relacionados com as condições gerais da vida (movimentos ambientalistas), motivados por desigualdades culturais (movimento negro, feminista), dedicados a questão trabalhista (sindicatos), voltados à defesa dos direitos humanos, e os vinculados a problemas específicos (associações de catadores de lixo). Além dessa segmentação, todos esses movimentos sociais estão distribuídos naturalmente entre os de âmbito urbano e rural.

Os movimentos sociais rurais no Brasil surgem da efervescência dos conflitos do campo que marcam a história do desenvolvimento e ocupação do nosso país. As primeiras disputas de terra ocorreram há mais de 500 anos com a chegada dos europeus, resultando no genocídio de indígenas. Simultaneamente, os escravos lutavam contra os seus senhores e fugiam, formando assim os quilombos, alvo também de conflitos de terra. Posteriormente, foram os posseiros que passaram a lutar contra os grandes latifundiários e grileiros. Esses conflitos permanecem até hoje em uma nova conjuntura e com o envolvimento de outros sujeitos sociais. Só no ano de 2012 foram registrados 1.067 conflitos de terra no Brasil, envolvendo mais de 460 mil pessoas, sendo a região Nordeste líder no número de confrontos ${ }^{3}$.

Segundo Oliveira (2001, p.190) nas décadas de 1950 e 1960 as ligas camponesas "sacudiram o campo" e ganharam projeção nacional, mesmo com algumas de suas lideranças assassinadas. Na época foi criada a Confederação dos Trabalhadores da Agricultura (Contag) pelo governo de João Goulart que iniciou um processo de Reforma Agrária, mas que logo foi sufocado pelo golpe militar de 1964.

"Se a violência gera a morte, gera também as formas de luta contra a morte" (OLIVEIRA, 2001, p.193) e dessa contradição surge o Movimento dos Trabalhadores

\footnotetext{
${ }^{3}$ Dados retirados do relatório Conflitos no Campo - Brasil 2012.
} 


\section{Revista ComSertões}

Rurais Sem Terra (MST), afirma o autor. O MST surgiu há 33 anos em Cascavel, no Paraná, e hoje é o movimento rural mais organizado e expressivo do país. Sua principal bandeira é a luta pela reforma agrária, posse e acesso ao uso de terras para todas as pessoas que nela trabalham estabelecendo um limite máximo a cada propriedade.

Apesar da visibilidade que o MST obteve ao longo dos anos - mesmo que de forma negativa quando criminalizado pela grande mídia - ele não é o único movimento social do campo brasileiro. Dentre um grande número de movimentos de luta no campo, Oliveira (2001) destaca: a luta dos povos indígenas pela demarcação de seus territórios; a luta pela terra de trabalho realizada pelos posseiros; a luta dos peões contra apeonagem ("escravidão branca"); a luta dos camponeses contra as desapropriações de terra para a execução das grandes obras do Estado, onde se destaca o Movimento dos Atingidos por Barragens (MAB). Há também a luta de camponeses pela permanência dos Fundos de Pastos ${ }^{4}$ aqui na Bahia.

Aliado aos movimentos do campo e os demais, surge o movimento pela democratização da comunicação, que combate o monopólio dos meios de comunicação, a falta de pluralidade, o desrespeito aos direitos humanos, e a criminalização de movimentos sociais e de minorias na mídia.

No final da década de 1970, a Organização das Nações Unidas para a Educação, a Ciência e Cultura (Unesco) elaborou um relatório "Um mundo, muitas vozes" trazendo para o debate público o tema do direito a comunicação, tratando como comunicação algo além do que a simples recepção de informação. Esse documento foi muito significativo na luta pela democratização da comunicação, chegando a impulsionar a criação da Nova Ordem Mundial da Informação (NOMIC), que tinha como membros nomes como Gabriel García Márquez e Paulo Freire, e que estimulou o debate desse tema a nível internacional.

Os princípios da NOMIC apontavam claramente a necessidade de transformar os sistemas de comunicação, pondo fim ao monopólio dos meios e respeitando a diversidade cultural dos povos. Os países que não estavam de acordo com a proposta de

\footnotetext{
${ }^{4}$ Modo tradicional de viver, caracterizado por fazer uso coletivo da terra e dos recursos naturais de um território, no qual a área ao fundo no entorno das roças familiares é usada para pastagens de animais, principalmente caprinos e ovinos.
} 


\section{Revista ComSertões}

mudança, onde a população iria ter mais acesso à produção e difusão das informações, agiram no sentido de desarticular o movimento, inclusive interferindo na liberação de recursos destinados a UNESCO (SILVA, 2010, p. 38).

No Brasil, esse debate teve início no princípio dos anos 1980 com o processo de redemocratização. As discussões sobre comunicação popular e comunitária começaram a ser difundidas em várias partes do país, ganhando espaço nos cursos de comunicação e na Igreja Católica, sobretudo nas Comunidades Eclesiais de Base (CEB's) com a formação de comunicadores populares. Segundo Moreira (2012), na década de 1990 destaca-se a ação da Frente Nacional pela Democratização da Comunicação (FNDC), que reunia entidades como a Federação Nacional de Jornalistas (Fenaj), a Executiva Nacional dos Estudantes de Comunicação (Enecos) e a Associação Brasileira de Radiodifusão Comunitária (Abraço). Segundo a autora, os movimentos de comunicação alcançaram poucas conquistas como a Lei de Radiodifusão Comunitária ${ }^{5}$ e a Lei do Cabo de $1995^{6}$. No ano de 2009, foi realizada a I Conferência Nacional de Comunicação $^{7}$, na qual foram apresentadas 617 propostas (muitas delas relativas à comunicação comunitária), mas que não receberam nenhum encaminhamento pelo governo.

A lei que orienta o serviço de comunicação no Brasil hoje (Código Brasileiro de Telecomunicações - CBT Lei 4.117 de 1952) tem mais de 50 anos, ou seja, está tão defasada que não contempla os desafios da convergência tecnológica, nem garante a liberdade de expressão para todos. Enquanto um novo marco regulatório das Comunicações não é realizado no país, a comunicação popular e comunitária em conjunto com os movimentos sociais são os sujeitos que desenvolvem uma comunicação mais democrática.

\footnotetext{
${ }^{5}$ Lei 9.612. Bastante polêmica, por mais que regule o serviço de radiodifusão comunitária no Brasil, adota critérios que restringe o funcionamento das rádios.

${ }^{6}$ Lei 8.977. Regulamenta o serviço de TV a Cabo no Brasil, e determina que todo prestador de serviço tenha um canal dedicado ao serviço comunitário.

${ }^{7}$ As conferências são mecanismos de consulta pública criados pela Constituição para garantir maior participação popular na formulação e avaliação de políticas públicas. Elas fazem parte da tradição democrática brasileira, sendo convocadas sistematicamente em áreas como Saúde e Educação, e um dos grandes diferenciais do governo lulista foi a convocação constante de conferências nas mais variadas áreas e segmentos, inovando o debate de Cidades, Mulheres, Juventude etc. (Avritzerapud Moreira, 2012). Na área da Comunicação, um evento público nacional deste porte nunca tinha sido convocado pelo governo.
} 
Revista ComSertões

\section{A Comissão Pastoral da Terra}

Um dos objetivos do regime militar brasileiro na década de 1970 era ocupar a Amazônia com empreendimentos econômicos. Os militares chegaram a utilizar o slogan "uma terra sem gente, para uma gente sem terra", porém, esse espaço já era ocupado por várias comunidades indígenas e posseiros.

Nesse mesmo período, a Igreja Católica influenciada pela Teoria da Libertação ${ }^{8}$ começa a fundar as Comunidades Eclesiais de Base (CEB's) ${ }^{9}$. Nesse contexto, os bispos D. Pedro Casaldáliga, D. Fernando e D. Thomás Balduino criam a Pastoral da Terra, em 1975 na Amazônia, para defender os indígenas e posseiros dos impactos causados pela chegada dos colonos e empresas nessa região.

Na Diocese de Juazeiro, na Bahia, a criação da pastoral surgiu do mesmo intuito de defender as comunidades camponesas. Em 1976, estava em construção a barragem de Sobradinho, hoje o maior lago artificial da América Latina. Devido a essa obra, quatro cidades foram relocadas: Remanso, Casa Nova, Sento Sé e Pilão Arcado. Cerca de setenta e duas mil pessoas foram expulsas de suas terras de forma violenta e com indenizações irrisórias.

Nesse mesmo ano, havia chegado a Juazeiro o bispo Dom José Rodrigues, que juntamente com outros bispos e o apoio do Centro de Estudos e Ação Social (CEAS), dos jesuítas de Salvador, criaram a Pastoral da Terra da Bahia. Em 1977, o nome "comissão" acrescentou-se a pastoral, referindo-se a um grupo de pessoas, sejam eles padres, leigos ou religiosos, que atuam em conjunto.

$\mathrm{O}$ trabalho da CPT consiste em acompanhar as comunidades rurais, denunciar conflitos e opressões e apoiar a luta dos camponeses. Ela faz isto por meio de visitas as comunidades, formação, apoio jurídico e divulgação da realidade rural. A Comissão apoia também movimentos sociais como Movimento dos Trabalhadores Sem Terra (MST) e o Movimento dos Atingidos por Barragens (MAB).

\footnotetext{
${ }^{8}$ Movimento que engloba várias correntes de pensamento que interpretam os ensinamentos de Jesus Cristo em termos de uma libertação de injustas condições econômicas, políticas e sociais.

${ }^{9}$ Pequenos grupos organizados em torno da paróquia (urbana) ou da capela (rural), cujo objetivo é a leitura bíblica em articulação com a vida, com a realidade política e social do lugar onde vivem.
} 


\section{Revista ComSertões}

Após trinta e sete anos a CPT continua presente na Diocese de Juazeiro, realizando o mesmo trabalho. Milhares de famílias camponesas ainda sofrem com práticas como a grilagem de terras e investidas dos grandes empreendimentos do agro e hidro negócio, mais recentemente com a chegada de mineradoras e parques eólicos no estado da Bahia.

\section{A Comunicação da CPT}

Sob o comando de Dom José Rodrigues, a Diocese de Juazeiro a partir do início da década de 1980 começa a realizar o trabalho de formação de comunicadores populares, através do Setor Diocesano de Comunicação e Audiovisual (Sedica). Esses comunicadores formavam uma rede de correspondentes que abrangia os dez municípios da diocese, fortalecendo esse tipo de comunicação na região. O Setor de Comunicação funcionou até dezembro de 2010.

O antigo estúdio do Sedica e seus equipamentos estão agora sob a responsabilidade da CPT. São duas salas pequenas, uma com acústica para gravação de áudios e a outra utilizada para edição de vídeos. Dos equipamentos antigos são utilizados dois computadores e uma câmera filmadora.

A equipe de comunicação da pastoral é composta por um jornalista e alguns estagiários voluntários que comparecem eventualmente. As peças de comunicação produzidas com periodicidade pela CPT são: um programa de rádio semanal (A voz do Velho Chico), um boletim impresso bimensal (Caminhando) e a alimentação diária do blog e de redes sociais. Os outros produtos como spots, releases, vídeos, folders e cartilhas variam de acordo com a necessidade.

Esse trabalho é realizado com base em um plano de comunicação que tem duração de um ano. Nele, estão delimitados os temas de cada programa de rádio e boletim, e também suas possíveis fontes. Para os outros materiais estão estipulados os prazos de entrega.

\section{Análise dos produtos midiáticos}




\section{Revista ComSertões}

Seguindo o Plano de Comunicação da Comissão Pastoral da Terra, para o mês de março de 2013, estavam previstos a confecção destes materiais: quatro programas de rádio, sendo cada um com os seguintes temas, Dia da Mulher, Encontro das Mulheres de Fundo de Pastos, Sistematização das experiências populares e Semana da Água; o Boletim informativo sobre energia eólica e Semana da Água; quatro spots sobre mineração, energia eólica, grandes projetos e fundos de pasto; uma cartilha de sistematização sobre o fundo de pasto de Areia Grande em Casa Nova (BA); e a alimentação diária do blog e da fanpage do facebook.

O programa "A voz do Velho Chico" - que existe desde o final da década de 1980 - é exibido aos domingos das 7:00h às 7:30h da manhã na rádio Grande Rio AM, emissora líder com 75\% de audiência na região. Todas suas edições são iniciadas com a mesma abertura:

Antigamente era um rio de águas férteis, onde o peixe dava em abundância, sadio; o povo vivia tranquilamente em suas terras, convivendo com a agricultura nas vazantes, criando bode e ovelhas nas caatingas. Hoje, toda esta paisagem está mudando,é preciso despertar para essa mudança! A voz do Velho Chico: o programa que conta a verdadeira história do povo do Vale do São Francisco (Programa A Voz do Velho Chico).

Em seguida, o apresentador saúda os ouvintes de várias cidades e apresenta as atrações do dia. O programa tem uma dinamicidade, músicas animadas (sertanejo, forró) são incluídas na programação. Uma linguagem clara e objetiva também é utilizada, por exemplo, ao trocar a palavra "agrotóxico" por "veneno" em uma das matérias. "A voz do Velho Chico" tem um perfil educador e conscientizador. Até os comerciais possuem esse caráter, são campanhas sobre a valorização da mulher, convivência com o semiárido, impactos de grandes projetos, etc.

No mês em estudo, foram gravados e exibidos cinco programas radiofônicos "A voz do Velho Chico" e não quatro como estão no plano. Dos temas previstos, só o do Dia da Mulher foi realizado. Os outros assuntos abordados foram: o rio São Francisco, Agrotóxicos, instalação da Monsanto ${ }^{10}$ em Petrolina (PE), e a Semana Social da Diocese de Juazeiro. Todas as cinco edições seguiram a mesma estrutura, a discussão de

\footnotetext{
${ }^{10}$ Multinacional de agricultura e biotecnologia, líder na produção de herbicidas e transgênicos.
} 


\section{Revista ComSertões}

um único assunto com um entrevistado competente da área. Essas fontes geralmente são pessoas de movimentos populares e de outras pastorais sociais.

O boletim informativo "Caminhando" do mês de março, estava previsto para estar pronto no dia 18 de março, contemplando as temáticas sobre energia eólica e Semana da Água. Entretanto, ele saiu da gráfica no mês de abril, com uma tiragem de 1000 exemplares. O boletim é feito no formato A3, colorido, com papel de jornal e contêm quatro páginas.

Nesta edição do "Caminhando" foram abordados os temas dos impactos da chegada dos parques eólicos na região, saneamento básico, privatização das águas, usina nuclear e ameaças a comunidades de fundo de pasto. Todas as matérias foram produzidas pelo setor de comunicação da CPT, e nos moldes jornalísticos com a presença de lead, sublead e fontes. As notícias não se concentram em Juazeiro, abrangem várias cidades do Território do Sertão do São Francisco.

Todas as notícias do boletim vêm acompanhadas de fotos e legendas. O que chama a atenção é a linguagem utilizada no periódico, como podemos identificar nesses trechos: "O Estado vai na contra mão da história e agora quer empurrar goela abaixo uma usina nuclear..." (p. 04); "Com saudades da política do pau de arara e do choque elétrico da ditadura, o Estado repete os atropelos aos povos da terra... "(p.03).

Os spots foram feitos e entregues na data preestabelecida, exceto o que tratava sobre grandes projetos. Eles foram avaliados pela CPT do estado da Bahia, e posteriormente veiculados no programa "A voz do Velho Chico" e nas produções da CPT de outras cidades. A cartilha de sistematização de Areia Grande também foi realizada, com uma tiragem de duzentos exemplares, e utilizada em um seminário de Comunidades Tradicionais promovido pela CPT Nacional.

Durante o mês de março, o blog da CPT de Juazeiro ${ }^{11}$ somou 33 postagens. As atualizações da página predominantemente ocorreram de segunda a sexta-feira, em uma média de um post por dia, com oscilação de dois a quatro posts na mesma data. Os assuntos abordados nas notícias são relacionados com os seguintes temas, na ordem de maior relevância: comunidades tradicionais (fundos de pastos, quilombolas), impactos gerados por grandes projetos (mineração, energia eólica, hidrelétricas), relações

\footnotetext{
${ }^{11}$ Endereço do blog: http://cptjuazeiroba.blogspot.com.br/
} 


\section{Revista ComSertões}

trabalhistas (trabalho escravo, condições de trabalhadores), uso da terra (agronegócio, agroecologia, grilagens), e uso da água (conflitos, transposição). Abaixo o gráfico demonstra a porcentagem das notícias publicadas com esses assuntos:

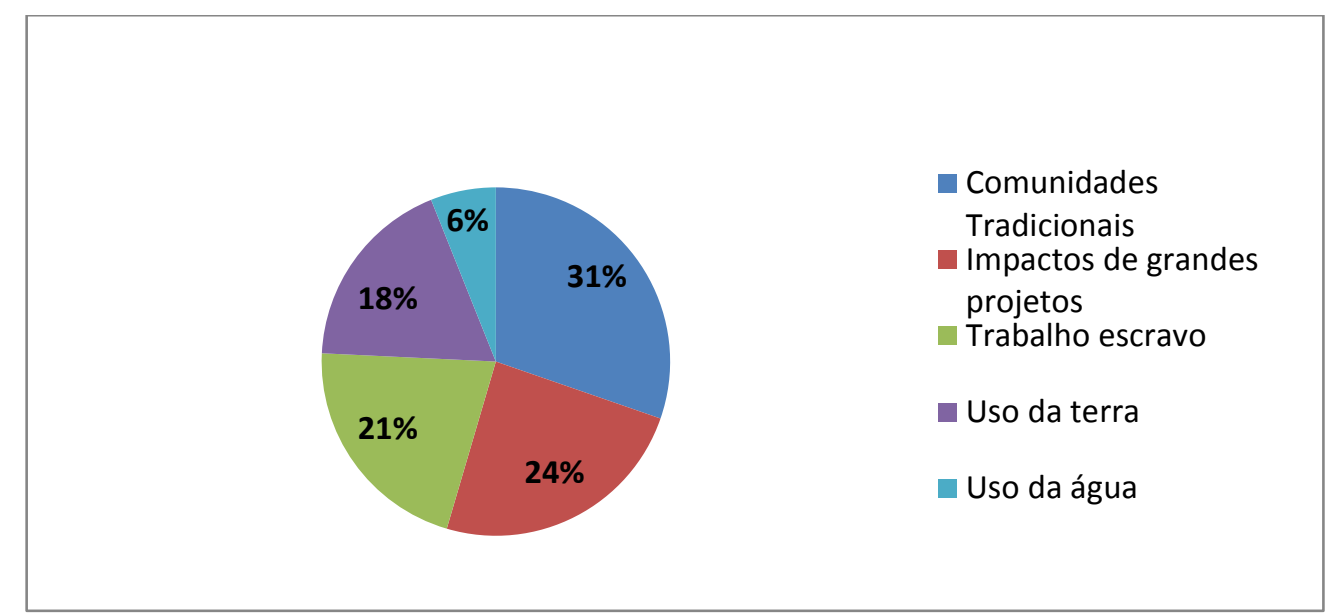

Gráfico 1: Temas das notícias publicadas no blog da CPT (Março de 2013). Fonte: Própria

Das trinta e três notícias, apenas seis tratam de conteúdos regionais, ou seja, relativos aos municípios que fazem parte da Diocese de Juazeiro, e consequentemente da abrangência da CPT. Dessas seis, somente quatro foram produzidas pelo setor de comunicação. São elas: "Casa Nova: Onde a lei não chega para famílias de Areia Grande", "Curso de Agroecologia promove troca de saberes em Juazeiro (BA)", "Comunidades tradicionais de Minas, Bahia e Pernambuco trocam experiências em seminário promovido pela CPT", e "Comunidades de Areia Grande clamam por Justiça em Casa Nova".

A primeira corresponde a um vídeo de cerca de três minutos. As outras três são notícias escritas dentro do padrão jornalístico. Todas as atualizações do blog foram postadas na fanpage, que conta atualmente com sessenta e seis pessoas que curtem a página. No mês de março, o blog da CPT de Juazeiro alcançou 1.260 visualizações.

\section{Considerações Finais}




\section{Revista ComSertões}

A comunicação feita na Comissão Pastoral da Terra faz parte do bojo que luta contra a hegemonia midiática. Ao dar espaço para vozes que estão historicamente reprimidas, a CPT assegura o direito à comunicação a essas pessoas - mesmo que momentâneo - e contribui para uma comunicação mais plural. Nos produtos confeccionados pela entidade, as fontes são primordialmente a camponesa, o homem do campo, membros de movimentos populares, pessoas que raramente aparecem na grande mídia, e que quando aparece não tem destaque e às vezes são criminalizadas.

A comunicação popular é feita em meio a muitas limitações. Peruzzo (1999) aponta algumas delas: abrangência reduzida, inadequação dos meios, uso restrito de veículos, falta de competência técnica, conteúdo mal explorado, instrumentalização e carência de recursos financeiros.

Podemos perceber algumas dessas limitações na CPT. Primeiramente precisamos entender que o trabalho da Comissão é muito descentralizado, são muitas comunidades assessoradas por ela, o que necessita de muita mobilidade. Um comunicador só não dá conta de estar em vários lugares, produzir vários materiais e ainda fazer a assessoria da entidade. A carência de recursos financeiros impede a contratação de pessoas, a aquisição e manutenção de equipamentos, e consequentemente a produção de um número maior de materiais.

Em decorrência disso, constatamos os atrasos de entregas de produtos e da elaboração de uma simples notícia para ser postada no blog. A tiragem de materiais que vão para a gráfica também é muito reduzida em comparação à quantidade de famílias camponesas que são acompanhadas. O conteúdo regional também é pouco explorado, não dá conta dos dez municípios que compõem o Território do Sertão do São Francisco. Nem no programa radiofônico, que alcança todas essas cidades, o conteúdo é diversificado.

O que Peruzzo (1999) denomina de "instrumentalização" é verificável também na CPT. Essa característica, segundo a autora, corresponde à utilização dos meios populares sempre com o intuito de conscientização/mobilização/transformação social. No boletim e no blog só é usado esse tipo de informação, às vezes com um tom até muito pesado. E por mais que as notícias produzidas apresentem, em partes, técnicas 


\section{Revista ComSertões}

jornalísticas como o lead, elas não apresentam fontes dos dois lados da situação, não ouvem as fontes ditas oficiais, reproduzindo sempre o discurso de um lado só.

Mesmo estando no ano de 2013, a CPT continua trabalhando sob o mesmo modelo de comunicação da década de 1970/1980 que vê a comunicação como libertadora, revolucionária, predominantemente composta de conteúdos críticos e reivindicativos. Atualmente esse modelo não predomina mais em organizações semelhantes, que costumam apresentar um discurso mais flexível.

Podemos perceber também que as novas tecnologias da informação e comunicação fazem parte da rotina da CPT. A Pastoral faz uso de vários meios de comunicação como cartilhas, boletim, programa radiofônico, vídeos, e internet. Dessa maneira os conteúdos são trabalhados de diversas formas em cada plataforma, atingindo públicos diferentes. O blog e fanpage, por exemplo, alcançam o público da zona urbana, e servem mais como instrumentos de divulgação da realidade camponesa (assessoria). Já o boletim imprenso, as cartilhas, e principalmente o programa de rádio chegam com mais facilidade ao meio rural.

\section{Referências Bibliográficas}

Conflitos no Campo - Brasil 2012 [Coordenação: Antonio Canuto, Cássia Regina da Silva Luz, Flávio Lazzarin[Goiânia]: CPT Nacional - Brasil, 2013.

GOHN, Maria da Glória. Cidadania, Meios de Comunicação de Massas, Associativismo e Movimentos Sociais. In: PERUZZO, Cicilia; ALMEIDA, Fernando (org). Comunicação para a Cidadania. São Paulo: INTERCOM; Salvador: UNEB, 2003.

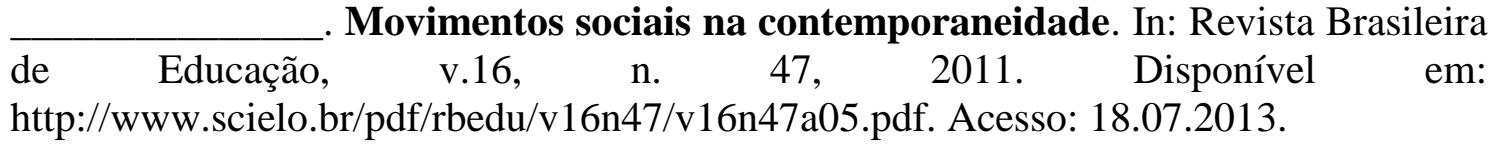

MARTÍN-BARBERO, Jesús. Dos Meios às Mediações: Comunicação, Cultura e Hegemonia. Rio de Janeiro: UFRJ, 1997.

MOREIRA, Gislene. É legal? A regulação da Comunicação Comunitária na esquerda latino-americana. In: Intercom - RBCC. São Paulo, 2013.

PERUZZO, Cicilia Maria Krohling. A comunicação nos movimentos populares: a participação na construção da cidadania. Petrópolis: Vozes, 1998.

OLIVEIRA, Ariovaldo Umbelino. A longa marcha do campesinato brasileiro: movimentos sociais, conflitos e Reforma Agrária. In: Estudos Avançados 15, 2001. 
Revista ComSertões

Disponível em: http://www.scielo.br/pdf/ea/v15n43/v15n43a15.pdf. Acesso: 18.07.2013.

SILVA, Érica. A Comunicação e as lutas pela água no Vale do Salitre. Juazeiro: UNEB, 2010. 